\title{
EFFECTIVE FACTORS ON THE ACCEPTANCE OF ELECTRONIC IN-SERVICE TRAINING BY HIGH SCHOOL TEACHERS; FORMULATING SOME ACTION PLANS TO DEVELOP E- TRAINING CASE STUDY: BANDAR ABBAS HIGH SCHOOL TEACHERS
}

\begin{abstract}
Mr. Naser Shams
M. Zarifi

MA industrial Engineering, Deputy Educational Technology Training Center Of Farzanegan In Bandar Abbas, Iran
\end{abstract}

\begin{abstract}
The development of information technologies and the impact of the telecommunication devises on the societies has changed and evolved the training methods as well. These changes are being occurred so that every person can do learning anywhere anytime through any device he/ she prefers. The development of the technology and its cheap costs has made the man to approach newer tools for transferring the knowledge in societies. This research aims to study the synergies of electronic training technologies in inservice programs for high school teachers. In this regard, this study attempts to explain the effective social, cultural, technical, technological and economic factors on the acceptance of such trainings, and to offer some action plans for promoting this type of trainings in high schools. To fulfill this objective, a questionnaire was formulated and distributed between the high school teachers in Iranian Bandar Abbas City to discover the most effective factors. After the reliability and validity of the questionnaire were confirmed, the collected data were analyzed using SPSS software. Obtained results show that the effectiveness of socio-cultural, technical-technological, and legal factors is confirmed but the economic factors don't show any effect on the acceptance of electronic in-service trainings by high school teachers.
\end{abstract}

Keywords: Acceptance, Effective Factors, Electronic Training In-service Training, 


\section{Introduction}

Nowadays, the application of the information and communication technologies is inevitable. Indeed, these technologies can solve many problems of traditional trainings of teachers including the needed time for attending in the school and interruptions in the school programs, lack of synchronization between the changes in the textbooks and the pace of education, locational and time limitations, etc. The mentioned type of trainings can provide modern methods for training the teachers.

Moreover, as a fundamental element in all educational programs, the teachers play a vital role in facilitating the learning and the effectiveness of the process of education. The increasing development of sciences and the necessity to change the educational system in our time makes the need for updated teachers a real concern of the educational system. Since the traditional approaches are no longer able to meet all educational needs of the teachers, the application of electronic trainings seems necessary and inevitable.

On the other hand, the importance of professional trainings of the teachers, especially the teachers of high schools seems undeniable because the high school is one of the most important grades of education with regard to its effect on the educational success of the students and its effect on the students' future pass and on the courses of studied they will approach in the universities. Accordingly, this research aims to study and analyze the effect of social, cultural, technical, technological and economic factors on the application of electronic in-service trainings of the teachers. Besides the identification of effective factors, this research emphasize on the level of this trainings in high schools.

\section{Problem statement}

With the development of electronic communications, distance learning has found new position and it has changed to be an educational solution for training the busy and employed individuals and those who cannot attend the schools and university to learn. The development and application of communicational technologies in educational systems is indeed a way of changing the educational process and it can facilitate the process of providing and receiving educational courses in different places (Murphy and Terry, 1998, quoted by Zamani and Moqaddasi). In discussing the role of ICT in the in-service teachers' training we have to remind that ICT by definition is to collect, organize, save and publish the data including audio, video, textual, or digital data using computer and telecommunication devices. ${ }^{4}$ Thus a suitable application of information and communication

\footnotetext{
${ }^{4}$ Available at: http://ict.moe.org.ir/usrFiles/UsrImages/ICT.jpg
} 
technology is its application in the teachers' in-service trainings. According to Garrison and Anderson, e-learning has inevitably changed all methods of learning and teaching in $21^{\text {st }}$ century and it will continue to be a vital vein of technology-based learning. Some of the most important capabilities of modern information and communication technologies in the teachers' inservice trainings are as follow:

a. Increased access to trainings and educational sources and materials;

b. Flexibility in teaching;

c. Deepened and durable trainings and improvement of the learning quality;

d. Reduced costs; the ICT-based trainings mainly have high fixed and low variable costs totally lead saving the money in large scales;

e. Providing organized opportunity for relearning along with acquiring new knowledge and skills;

f. Simultaneous training

g. Professional training of the teachers in a participatory method. The application of ICT can be put forward in different points of the country and to create "virtual learning groups of teachers" so that the teachers can share their experiences, plans, materials, booklet files, and participatory projects to other teachers.

The acceptance of technology and electronic trainings as a system is shown in the Technology Acceptance Model (TAM) (Figure 1)

Considering the advantages of electronic trainings and increasing application of these trainings in developed and developing countries, now the problem of the research can be formulated as follow: what is the effect of social, cultural, technical, technological and economic systems on the training components in general and on the teachers' in-service trainings in particular; and what strategies can be suggested for developing these technologies?

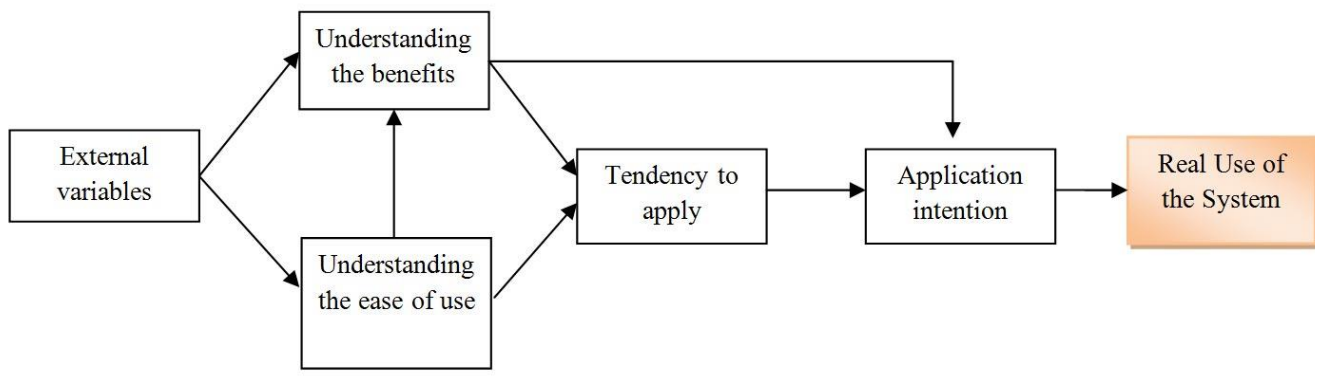

Figure 1. Technology Acceptance Model (TAM)

\section{Effecive factors in electronic in-service training systems}

In the conceptual model of the technology adoption (Figure 2) we see that different cultural, attitudinal, technical, managerial and pedagogical factors are involved. Moreover, facilitating conditions and providing 
different (technical, educational, legal, etc.) facilities are directly effective on the technology adoption as well. These factors in turn lead to attitude toward the technology use, educational compatibility, computers self-efficiency, and perceived usefulness; and all these factors finally lead to the technology adoption.

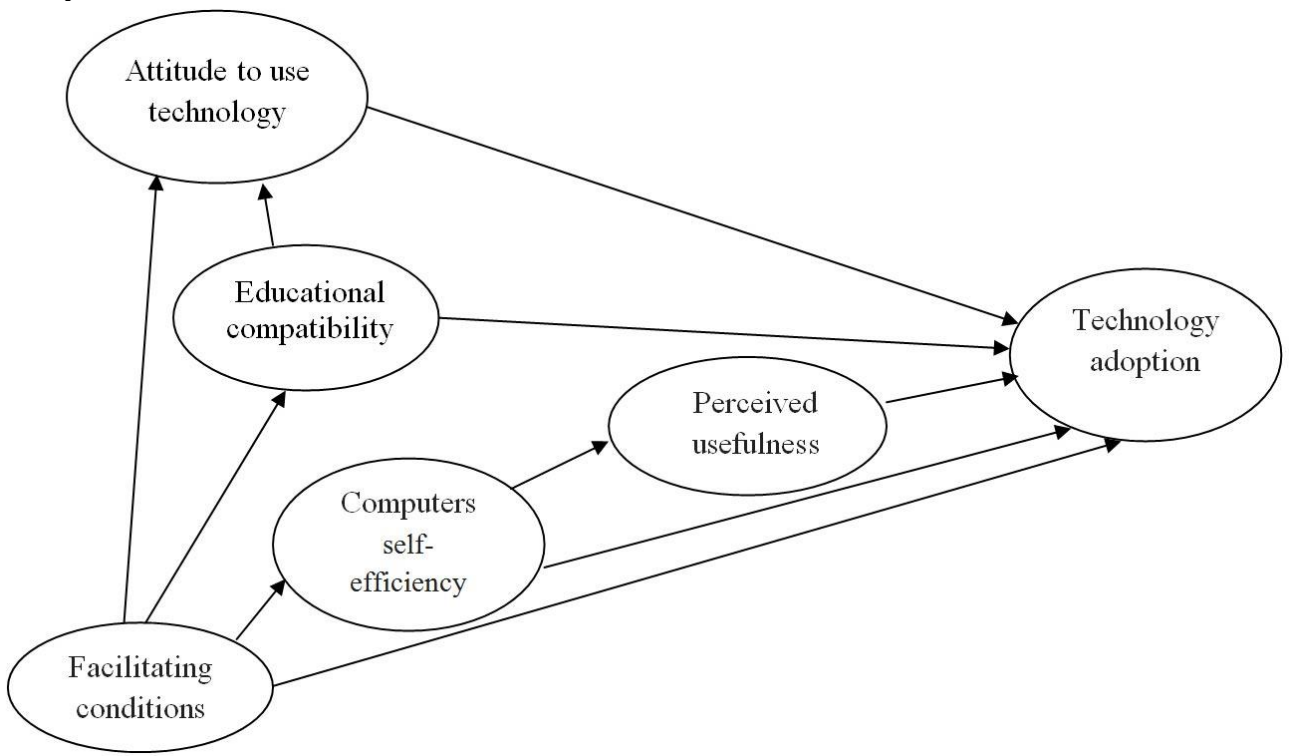

Figure 2. Prediction of technology application in learning (Chan, 2012)

\section{Literature review}

The original idea of using computers and computer networks for the scientific and educational applications roots in 1960s when the main objective of so-called APIIA project was to create a network for exchanging military data. But since 3 centers out of the 4 centers of the project were based in American universities, the APIIANET (which finally led to global internet network) was grown in an academic setting. The development of internet technology at the beginning of 1990s, electronic trainings grew rapidly to fix their position in the educational system of many countries of the world.

Iranian Ministry of Education implemented the "Iranian Comprehensive Informatics System" since 2000s. This system covers 4 dimensions: human resources, educational institute, courses, and students. The current Iranian electronic in-service training situation shows that more than $30 \%$ of the teachers' in-service trainings are administered on the electronic setting (Garmaroudi, 2012).

According to the available literature, most fundamental challenges of the electronic training in Iran include the socio-cultural barriers, electronic (software and hardware) barriers, legal barriers, pedagogical barriers 
(including cognitive, content, and educational barriers), and economic barriers (Razzaqi, 2008). The most relevant resources of the literature to our current studies are as follow:

- Chun Lai (2012) believes that there is a direct positive relationship between the perceived usefulness or uselessness of technology in learning, attitude to technology, facilitating conditions, application efficiency, and educational compatibility (skills of technology application) so that the educational compatibility is directly and positively related to the technology application. Moreover, the attitude to the technology has a strong effect on technology acceptance and technology-based learning. The other factor is ICT skills which are very effective on using the technology. Besides, Lai found that the students who have used technology in their bachelor learnings are more opt to accept the technology in other trainings.

- Hosseini (2007) found that the discovered barriers in the e-learning underdevelopment of Iranian educational system are significant. Sociocultural barriers have the highest effectiveness on the underdevelopment of e-training in Iran. The economic barriers stand at the second rank with regard to their effect on the underdevelopment of e-trainings. Then the legal barriers, pedagogical barriers (including cognitive, content, and educational barriers), strategic barriers, and technical and technological (including software and hardware) barriers stand on the next rank respectively with regard to their effect on the underdevelopment of electronic training in Iran.

- Nasiri (2011) found that there is a significant relationship between the electronic training and self-efficiency. Moreover she observed a significant relationship between electronic training and the effectiveness of such trainings on a 95\% confidence level. On the other hand, with regard to the demographical components (including the age, work experience and education) there is no difference between the electronic trainings and the studied factors. Additionally, there is no significance relationship between the age and education on one hand and the empowerment on the other hand, but the relationship between the empowerment and the work experience was found to be significant.

- Salehi (2011) found that the computer facilities and equipment are suitable for administrative affairs in Iranian schools; but these facilities and equipment are not desirable for educational affairs (i.e. students and teachers' use). Moreover, the ICT skills of teachers are not desirable but they have strong motivations for benefiting from the modern technologies.

Reviewing the scientific literature of the subject shows that it seems the following factors have been effective on the acceptance of electronic in- 
service trainings by the teachers: (1) socio-cultural factors; (2) economic factors; (3) technical and technological (software and hardware) factors; (4) pedagogical or educational (cognitive, content, and planning) factors; (5) legal factors; (6) strategic factors.

\section{Overview}

\section{Objective of the research}

The main objective of the research has been to study the synergies of electronic training technologies in in-service programs for high school teachers, focusing on the effective social, cultural, technical, technological and economic factors on the acceptance of such trainings, and to offer some action plans for promoting this type of trainings in high schools in general, and high schools of Iranian Bandar Abbas City in particular.

\section{Questions of the research}

- What are the most effective factors on the acceptance of electronic inservice trainings by the teachers?

- How the social, cultural, economic, technical and technological, and legal factors affect the acceptance of electronic in-service trainings by the teachers?

\section{Hypotheses of the research}

- There is a direct relationship between the socio-cultural conditions (age, gender, and education level, field of study, ethnicity, and geographical area) and the acceptance of electronic in-service trainings by the teachers.

- There is a relationship between the economic factors and the acceptance of electronic in-service trainings by the teachers.

- There is a direct relationship between the technical and technological (hardware and software) factors on one hand and the acceptance of electronic in-service trainings by the teachers on the other hand.

- There is a relationship between the legal factors and the acceptance of electronic in-service trainings by the teachers.

\section{Methodology, statistical population and sample}

This study is a descriptive-applied research which is applied one with regard to its objective. The nature of this research is descriptive-analytic with regard to its method of data collection, emphasizing on the correlation analysis method. The statistical population of the research includes all high school teachers of Iranian Bandar Abbas City who were teaching in 2012-13 
among which 100 teachers were selected as the sample of research using Morgan's Table Editor and a stratified random relative sampling method.

\section{Data collection and data analysis method.}

To collect the data we used a researcher-made questionnaire and the inferential and descriptive analyses were applied on the obtained results using Pearson's correlation test, variance analysis and independent $\mathrm{T}$ test in SPSS software. In order to cover the questions of the research we used frequency, percentage, mean and chart, unidirectional t-tests and the exploratory factor analysis.

\section{Effective factors on the acceptance of electronic in-service trainings by the teacher}

In all in-service trainings we should keep in mind virtually that the cultural context is the most fundamental support of barrier of any changes in the societies; and the socio-cultural characteristics are a good setting for introducing new technologies into the societies. Besides emphasizing on the fundamental role of cultural context in supporting the application of new technologies in training the human resources, other factors that have to be considered are as follow: common viewpoint of the members of a group, accessibility to the technologies, professional qualification of the trainers, technical cooperation, attitude to the training, and evaluating the supportive policies (Shams, 2005).

\section{Socio-cultural factors}

Among the most important socio-cultural factors that are effective on the acceptance of electronic in-service trainings we can refer to the age, gender, education level, field of study, ethnicity, and geographical area.

a) Age: being interested in new learning and teaching methods require spending more energy, seeking diversity, and being open to new experiences. It is expected that the rise of the age increase the resistance of individuals against the acceptance electronic in-service trainings.

b) Gender: in his book titled Individual differences, Hamzeh Ganji refers to the existing differences between their genders and the effect of these differences on learning and teaching. According to him, the different visual and auditory perception, skills and senses of the two genders show a significant difference. These differences will distinguish the two genders in their learning methods and consequently in their acceptance of electronic trainings.

c) Marital status: since the married persons are usually busier and their time for learning is more limited than the single persons, it is expected that the acceptance of electronic in-service trainings is different by the 
married and single teachers. Moreover, since the single persons have more free time to work with computers, this point has to be considered and reflected in the results of the research.

d) Education level: since the higher education is the business of dealing with different methods of learning, it is expected that the teachers with university education are more interested in electronic learning and so the acceptance of electronic in-service trainings will be higher by them than the other teachers.

e) Field of study: different fields of study are different by nature in using updated sciences. During their study, the students must coordinate their own learning and educational system with different learning methods and systems. This obligation in some fields such as the technical and engineering fields of study is higher than humanities. So it is expected that the graduates of the engineering fields of study welcome the new learning methods (such as the electronic trainings) than for example the graduates of the humanities.

f) Ethnicity: do the mental structures of the individuals from different ethnicities affect their acceptance of the educational and learning methods? This is a socio-cultural factor that we attempt to study in this research.

\section{Economic situation}

According to the available studies in the literature, next to the sociocultural factors, economic barriers have to be placed in the second rank of the effective factors on the underdevelopment of electronic learning.

\section{Technical and technological (software and hardware) factors}

Another group of factors that has to be studied is the efficiency of hardware and software factors, computers knowledge, and connectivity to the network with regard to their effectiveness on the acceptance of electronic trainings by the target population. This group includes some factors as follow:

a) Level of computer knowledge and literacy: lack or shortage of teachers' computer knowledge is one of the main problems and reasons for "informational underdevelopment" and "cultural underdevelopment". Computer literacy is indeed the knowledge of the requirement of information age and the ability to use informational applications. The computer literacy is one of the most important prerequisites of the active and smart participation in this area.

b) Owning a computer: the educational need for electronic learning will be met if all teachers access to internet-connected computers. This is while 
such an access is not possible for many teachers in remote cities and villages.

c) Level of traditional trainings: it seems that the traditional methods of learning are effective on the formation of learning habits in persons; and the higher amount of attending in traditional in-service training can be effective on resistance against the change of method from traditional one to the modern electronic method due to the unconventional nature of the educational environments.

d) Level of electronic trainings: perceived usefulness or uselessness of technology in learning, attitude to technology, facilitating conditions, application efficiency, and educational compatibility (skills of technology application) so that the educational compatibility is directly and positively related to the technology application. Moreover, the attitude to the technology has a strong effect on technology acceptance and technology-based learning. The other factor is ICT literacy which is very effective on using the technology. It is expected that the persons who have been affected more by a method, tend to keep continuing that methods more than the others.

\section{Legal factors}

It seems that the characteristics of the persons with different official posts and positions, their level of business, their time and place limitations, their status of employment (the nature of their contract) of the target population is effective of accepting the type of in-service trainings. This dimension is another factor that was focused in this study with regard to its effectiveness on the acceptance of electronic in-service trainings in the target population.

a) Position: in their research on relationship between the electronic inservice trainings and the empowerment of high school teachers, Nasiri, et al. (2011) found that there is not any significant relationship between the demographic variables (gender, work experience, and education) and the electronic learning; but the relationship between the empowerment and work experience of the subjects is significant.

b) Type of the employment: the next important factor is the official and legal status of the teachers with regard to their type of the contract (including official/non-official and part-time/full-time nature of their employment). It seems that the official full-time teachers are more open to accept new learning methods because their job is secure and they have specific plans for their job and intend to continue their job as teacher. 


\section{Findings of the research Socio-cultural factors}

Socio-cultural factors (age, gender, education level, field of study, ethnicity, and geographical area) have the highest rate of effectiveness on the acceptance of electronic in-service trainings in Iran. The qualitative and quantitative development of the electronic training requires the development of all educational management systems.

a) Age: being interested in new learning and teaching methods require spending more energy, seeking diversity, and being open to new experiences. Since the electronic training is a new method, it is expected that the teachers in different ages show different reactions to the acceptance of electronic training as a method that depends on special systems and facilities. Moreover, it is expected that the resistance against the electronic training increases with the rise of the age. According to the findings of this research, the highest mean of accepting electronic trainings belonged to the teachers with 40 to 45 years old, and the lowest rate of accepting electronic trainings belonged to the teachers with 30 to 35 years old. Variance analysis shows no significant difference at 0.05 level of significance $(\mathrm{p}=0.548>0.05$ ). Thus the significant relationship between age groups in accepting the electronic trainings (and consequently the hypothesis of the research) is rejected and the effect of the age on the acceptance of electronic in-service trainings by the subjects of the research is not confirmed.

b) Gender: in this research we compared the acceptance of electronic inservice trainings by two gender groups. The findings showed that there is a significant difference between the male and female teachers with regard to the acceptance of electronic in-service trainings. The comparison of the obtained means show that the mean of the acceptance of electronic in-service trainings in men is higher than women. Thus the first hypothesis of the research is confirmed for the effectiveness of the age factor on the acceptance of electronic in-service trainings.

c) Marital status: since the married persons are usually busier and their time for learning is more limited than the single persons, it is expected that the acceptance of electronic in-service trainings is different by the married and single teachers. The findings of this research show that there is no significant difference between the married and single subjects in terms of their acceptance of electronic in-service trainings. Thus the effectiveness of marital status on the acceptance of electronic in-service trainings by the target population is rejected.

d) Level of education: considering the qualitative and quantitative development of Iranian universities and the increase of using digital, audio and video media in education, the previous students who are now 
the teachers are willing to use diverse educational media and make them interested in learning new and different methods. The findings of this research showed that there is no significant difference between different educational levels in terms of their acceptance of electronic in-service trainings; and so the hypothesis of the research concerning the effectiveness of the education level on the acceptance of electronic inservice trainings is rejected. This finding is consistent with the findings of another research entitled the "the relationship between education and empowerment of secondary school teachers Famenin city" that showed there is no significant difference between the demographic factors (including gender, education level, and work experience) and e-learning (Nasiri, et al, 2011).

e) Field of study: different fields of study are different by nature in using updated sciences. During their study, the students must coordinate their own learning and educational system with different learning methods and systems. This obligation in some fields such as the technical and engineering fields of study is higher than humanities. Thus the teachers' field of study was considered as one of the effective factors on the acceptance of electronic in-service trainings. The obtained findings showed no significant difference between the teachers with different fields of study in terms of their acceptance of electronic in-service trainings and hence the relevant hypothesis of the research is rejected.

f) Ethnicity: the necessity of studying the mental structures of the individuals of different ethnicities and their effect on the acceptance of educational methods made us consider the ethnicity as a factor under the cultural group of factors. According to the findings of the field studies, we found that there is no significant difference between two ethnical (local and non-local) groups and hence the effect of ethnicity on the acceptance of electronic in-service trainings by high school teachers of Iranian Bandar Abbas City was not confirmed.

\section{Economic situation}

A very important educational factor in this area is the educational economy that shows the mutual effects of economy and education on each other. According to the available studies in the literature, next to the sociocultural factors, economic barriers have to be placed in the second rank of the effective factors on the underdevelopment of electronic learning. The rate of wages and salaries, and the suitability of the teachers' economic situation were studied under the economic factors. The results of the descriptive statistics for the acceptance of electronic in-service trainings by the teachers in different economic welfare show that the highest mean of acceptance belonged to the group of average economic situation, while the lowest rate of 
acceptance belonged to the group of low economic situation. Moreover, the variance analysis for comparing the acceptability of electronic training among different economic situations showed that the difference between the mentioned groups in terms of accepting electronic training is not significant and thus the relevant hypothesis of the research is rejected.

\section{Technical and technological (software and hardware) factors}

a) Level of computer knowledge and literacy: according to the results of the descriptive statistics for the acceptance of the electronic in-service trainings by the teachers with different levels of computer literacy, the highest mean belonged to the group of "proficient" and the lowest mean belonged to the "weak" group of computer literacy. Moreover, the variance analysis for comparing the acceptability of electronic training among the groups with different levels of computer literacy showed that the difference between the mentioned groups in terms of accepting electronic training is significant and thus the relevant hypothesis of the research is confirmed. Additionally, the paired comparison of the acceptance of electronic in-service trainings among different groups showed that the weaker computer literacy the lower acceptance of electronic in-service trainings.

b) Owning a computer: statistical analyses show that there is no significant difference between computer-owned group and computer-less group in terms of the acceptance of electronic in-service trainings. Thus the relevant hypothesis of the research about the effect of owning a computer on the acceptance of electronic trainings is rejected.

c) Level of traditional and electronic trainings: analysis of the level of passed traditional and electronic training courses by the teachers of the research show that there is no significant difference between the two groups in terms of the acceptance of electronic in-service trainings. Thus the relevant hypothesis of the research on the effectiveness of the level of passed traditional and electronic training courses on the acceptance of electronic in-service trainings is not confirmed.

\section{Legal factors}

a) Position: descriptive statistics on the acceptance of electronic trainings in the subjects with different official posts and positions show that the highest mean of accepting electronic in-service trainings relates to the group of managers, and the lowest mean belonged to other positions. Nonetheless, the variance analysis for comparing the acceptability of electronic training among the groups with different official positions showed that the difference between the mentioned groups in terms of 
accepting electronic training is not significant and thus the relevant hypothesis of the research is rejected.

b) Type of the employment: the findings of the tables of research using independent t-test to compare the acceptance of electronic in-service trainings between two groups of "official teachers" and "unofficial" teachers show that there is a significant difference between the two groups in terms of the acceptance of electronic in-service trainings. Moreover, the comparison of the means show that the mean of the acceptance of electronic in-service trainings by the official teachers is higher than unofficial teachers, thus the relevant hypothesis of the research concerning the effect of the type of employment on the acceptance of electronic in-service trainings is confirmed.

\section{Suggestions and solutions for developing the acceptance of electronic in- service trainings by the high school teachers}

Since the perceived usefulness or uselessness of technology is effective on the learning, and the attitude to technology, facilitating conditions, and efficiency are directly related to the technology use, thus it is necessary to create positive attitudes before administering the electronic inservice trainings.

On the other hand, ICT literacy and skills are highly effective on the acceptance of electronic in-service trainings. Thus the teachers need to acquire ICT literacy and skills before attending any electronic in-service training course. Moreover, technical and technological (hardware and software) barriers have to be overcome because such barriers play an effective role in the underdevelopment of e-learning.

Since the age, marital status, level of education, field of study, ethnicity, economic situation, owning personal computer, level of passed inservice training courses, and the posts and positions of the teachers are not effective on the acceptance of electronic in-service trainings, thus the educational planners can plan in-service courses regardless of the age, marital status, level of education, field of study, ethnicity, economic situation, owning personal computer, level of passed in-service training courses, and the posts and positions of the teachers.

Additionally, since the difference between the computer-literate and computer-illiterate persons was significant in terms of the acceptance of electronic in-service trainings and the relevant hypothesis of the research was confirmed, thus it is necessary to promote the computer literacy of the teachers before administering electronic in-services trainings for the teachers.

Finally, since the mean of the acceptance of electronic in-service trainings by the official and unofficial teachers was significantly different 
and the official teachers had a higher mean than the unofficial teachers (confirming the relevant hypothesis of the research), thus it is suggested to focus on the official teachers for administering electronic in-service trainings.

\section{Reference:}

Asadi Garmaroudi, Asadollah, (2010), Informing Center of Iranian Ministry of Education, Tehran: Center for Planning and Training Human Resources in Iranian Ministry of Education, available at: <http://tstc.medu.ir> [in Persian]. Izi, Maryam, (2007), Educational Factors of the Underdevelopment of Elearning in Iranian Education, Tehran: Sarmayeh [in Persian].

Perraton, H., Robinson, B., \& Creed, C. (Eds.) (2007). International case studies of teacher education at a distance, translated by Ali Arabani Dana, Tehran: Distance Learning Institute [in persian].

Hosseini, Maryam, Mir Arab, Reza, and Rezaei, Saeid, (2007), Barriers of Developing the E-learning in Iranian Educational System, Tehran: First National Conference on E-learning [in Persian].

Razzaqi, Samira, (2010), Effective Factors on the Development of Virtual Universities in Iran, MA dissertation, Tehran: Tehran University Press [in Persian].

Zamani, Qolamhossein and Moqaddasi, Shahram, (2009), "Distance Learning: An Alternative Method in in-service Training of the Staff", Danesh-e Modiriat Quarterly, No, 39-40 [in Persian].

Zamani, Eshrat and Azimi, Seyyed Amin, (2008), "Exploiting ICT in Solving the Problems and Tasks of Science in UK Elementary Grades" Educational Innovations Quarterly, No. 27 [in Persian].

Salimabadi, Sara, (2006), Barriers of the development of Virtual Universities in Iran, MA dissertation, Tehran: Tehran University Press [in Persian].

Shams, Mohammad Shahab, (2004), Information and Communication Technologies in Education, Tehran: Sarmayeh [in Persian].

Nasiri, Fahime and Fathi Vajargah, Kourosh, (2004), Planning for in-service Trainings for the Staff, Tehran: SAMT [in persian].

Garrison, Randy and Anderson, Terry, (2004), Learning in the 21st Century: A Framework for Research and Practice, translated by Mohammad Attaran, Tehran: Institute for Developing Educational Technologies in Smart Schools [in Persian].

Nasiri, Fahime and Fathi Vajargah, Kourosh, (2005), "Feasibility of Establishing Virtual in-service training System in Iranian Ministry of Education", Tehran: Educational Innovations Quarterly, No. 27 [in Persian]. Dean, C. (2006),an overview of authoring systems and learning management systems available in the uk ,http://www.peakdean.co.uk. 
Harris, j. (2002), An Introduction to Authoring tools, ASTD, S learning Circuits online magazine.

Collis, B and Moonen J. (2003) Flexible Learning in a Digital Word: Experiences and Expectations ,London: Kogan Page.

Alestalo, M. H. and U. pletola. (2006)“The Problem of a Market - Oriented University"; Journal of Higher Education, vol.52,pp.251 - 281

Lai,Chun (2012) What factors predict undergraduate students use of technology for learning? A case from Hong Kong.Computers \& Education //www.elsevier.com

Bostjan Sumak(2009) Factors Affectting Acceptance and Use of Model: An Empirical Study Based on TAM- University of Maribor. 